\title{
Bone Mineral Content and Body Composition in Overweight Children and Adolescents
}

\author{
PIERRE M. BRAILLON AND ADRIAN SERBAN
}

Departments of Pediatric Imaging [P.M.B.] and Endocrinology [A.S.], Hôpital Debrousse and University Claude Bernard, 69322 Lyon, France

\begin{abstract}
The aim of this study was to analyze the bone mineral content (BMC) of the skeleton and the body composition in lean and fat masses in a population of young overweight subjects, before diet or medical intervention. A total of 496 white youths (298 females, 198 males) were studied. Their body mass index (BMI) values were $29.2 \pm 5.5 \mathrm{~kg} / \mathrm{m}^{2}$ in females and $28.3 \pm 5.1 \mathrm{~kg} / \mathrm{m}^{2}$ in males, corresponding to relative weights (wts) [actual wt, $\mathrm{W}$, divided by the mean wt normal for height (ht), Wi] of $1.55 \pm 0.24$ and $1.53 \pm 0.24$, respectively. Whole-body dual-energy x-ray absorptiometry (DXA) scans were performed (Norland XR36 DXA system) to obtain the total BMC (BMCt), lean tissue mass (LTMt) and fat mass (FMt), as well as the values of the corresponding parameters in arms (a), legs (1), and abdomen (ab). The measured data were compared with theoretical values calculated for $\mathrm{Wi}$. The differences with reference values in LTMt and FMt were sex dependent, and the accretion in FMt, greater in males than in females, yielded a similar FMt/LTMt ratio in both sexes. The wt corresponding to the BMC of the bearing skeleton, lower than the actual wt by about $20 \%$, seemed a reasonable first step to consider in the wt management of these youths. (Pediatr Res 62: 462-467, 2007)
\end{abstract}

$\mathrm{T}$ The prevalence of overweight and obesity among children and adolescents is rapidly increasing in industrialized populations as well as in developing countries where lifestyles are rapidly changing (1-8). Because health risks and associated diseases increase as wt increases $(9,10)$, monitoring body $\mathrm{wt}$, and more specifically the fat mass, during the growth period is necessary. First of all, to bring the wt of overweight youths as close as possible to their healthy wt for ht and, thus, to prevent the development of chronic conditions such as type 2 diabetes or cardiovascular diseases (10-14). The technical problem of body composition assessment has become relatively simple, and several methods are available. With its high precision, low irradiation dose (15), relatively low cost, and immediate delivery of precise results, dual energy x-ray absorptiometry (DXA) is certainly one of the most appropriate techniques. Although DXA can give values that differ from other methods, such as bioelectrical impedance analysis or total body electrical conductivity, since its pioneer use to measure body composition by Mazess et al. (16), several papers have shown that the technique is close to total body potassium for the assessment of fat-free mass (17), highly correlated with other methods $(18)$, and accurate $(19,20)$. It is also very sensitive to

Received December 6, 2006; accepted May 22, 2007.

Correspondence: Pierre M. Braillon, M.D., Ph.D., Department of Pediatric Imaging, Hôpital Debrousse, 29 Rue Soeur Bouvier, 69322 Lyon, Cedex 05, France; e-mail: pierre.braillon@chu-lyon.fr small changes in body composition $(21,22)$. Therefore, DXA seems to be a simple technique to measure the body composition in overweight subjects.

The main objective of the present work was to analyze the bone mineral content (BMC) of the entire skeleton, and the body composition in LTM and fat mass in a population of overweight youths, before any diet or medical intervention. The BMC of the arms and legs, their lean and fat masses, as well as the lean and fat masses at the abdomen level were also obtained. Data were compared with the corresponding mean values calculated for the ideal wt for ht by using the equations of correlation previously established in a reference population of the same French origin (23). Finally, the body wt that would be appropriate to the measured bone mineral content $(\mathrm{BMCj})$ value was estimated to define a reasonable horizon in the wt management for each patient.

\section{METHODS}

Subjects. A white population of 496 overweight children and adolescents (298 females, 198 males), with age ranging from 3.5 to $18.7 \mathrm{y}$, was studied at the time they entered a body wt control program. These subjects were randomly chosen in a population of overweight coming from the French middle class. They did not present any other known disease and therefore were under no particular treatment. The degree of overweight was defined from their BMI and was evaluated with reference to the ideal mean wt (Wi) for their actual ht $(\mathrm{H})$. This wt was calculated by using equations of correlation given in Appendix 1, and the ratio $\mathrm{K}=\mathrm{W} / \mathrm{Wi}$ was used. The DXA scans, which were part of the clinical assessment defined in this study, were approved by the Review Board of Hôpital Debrousse. The subjects and their parents were clearly informed of the details of the program, especially those related to DXA measurements, and gave their consent.

DXA scanning. Whole-body DXA scans of the patients were performed on a Norland XR36 DXA system. The following scanning parameters were used: pixel size, $6.5 \mathrm{~mm} \times 13.0 \mathrm{~mm}$; and scan speed, $260 \mathrm{~mm} / \mathrm{s}$.

Possible influence of fat on bone results. To define the possible correction to apply to BMC values due to the body fat increase, a spine phantom provided by the manufacturer of the DXA scanner was scanned in 10 sessions of five measurements each, with and without the addition of a polymethylmethacrylate (PMMA) block, covering the entire phantom and $58 \mathrm{~mm}$ thick. Measured with the DXA spine protocol, this PMMA block was equivalent to extra-lean and extra-fat masses of $40.0 \mathrm{~g}$ and $94.3 \mathrm{~g}$ per centimeter of thickness, respectively, while no bone equivalent was added.

Statistics. The usual methods of correlation were used. Tests (normality test of Kolmogorov-Smirnov; $t$ tests) were performed with SigmaStat V. 3.5 (Systat Software Inc., Point Richmond, CA).

Data analysis. Data used in this study corresponded to the results obtained by using the standard analysis software for whole-body scans. Total and regional data (arms, legs, and abdomen, the latter region being delimited by

Abbreviations: BMC, bone mineral content; $\mathbf{B M C j}$, measured bone mineral content; BMCt-h, BMC total less BMC of the head; DXA, dual energy X-ray absorptiometry; FMj, Measured fat mass; LTMj, measured lean tissue mass; Wskel, theoretical body weight calculated for BMCt-h 
the last ribs and the ischium) were studied. Bone data were noted $(j=t, a, l$, standing for total, arms and legs). Similarly, lean tissue mass and fat mass results were given as LTMj and FMj, respectively $(j=t, a, 1$, and $a b$ for abdomen). These values were compared with the corresponding reference values, BMCji, LTMji, and FMji, calculated for the ideal wt Wi and derived from previous work that included 166 control subjects ages $2.5 \mathrm{y}$ to $21 \mathrm{y} \mathrm{(23).}$ Correlations between the ratios bt $=\mathrm{BMC}$ total $(\mathrm{BMCt}) / \mathrm{BMC}$ total less $\mathrm{BMC}$ of the head (BMCti), lt $=\mathrm{LTMt} / \mathrm{LTMti}$, or $\mathrm{ft}=\mathrm{FMt} / \mathrm{FMti}$ and $\mathrm{K}=\mathrm{W} / \mathrm{Wi}$ were calculated, and FMt/LTMt values were compared with the FMti/LTMti ratios. The differences between the measured and the reference values are given hereafter with the prefix $\Delta$. Finally, the theoretical body wt calculated for BMCt-h (Wskel) would be appropriated, and the values of the ratios Wskel/W and Wskel/Wi were estimated. For that purpose, it was considered that the head plays no mechanical role in the skeleton, and its BMC was subtracted from BMCt, yielding to a parameter more representative of the bearing skeleton and noted as BMCt-h. Equations of correlation between W and this corrected BMC were used (unpublished data; equations given in Appendix 2).

\section{RESULTS}

Subjects' height and weight. The anatomical data of the subjects studied (Table 1) show that the ratio $\mathrm{k}=\mathrm{H} / \mathrm{Ha}$ (Ha: normal ht for age) had mean values of $1.05 \pm 0.05$ in both sexes, whereas the mean values for $\mathrm{K}=\mathrm{W} / \mathrm{Wi}$ were close to 1.5 (Table 1). These ratios were not significantly dependent on age $(p<0.001)$.

In vitro data. Although the superposition of the PMMA block on the spine phantom was equivalent to a threefold increase in its lean value and a 3.8 -fold increase in its fat value, the measured BMD and BMC values showed small changes: $1.020 \pm 0.007 \mathrm{~g} / \mathrm{cm}^{2}$ versus $1.027 \pm 0.008 \mathrm{~g} / \mathrm{cm}^{2}$ $(\Delta=0.7 \%)$, and $42.80 \pm 0.30 \mathrm{~g}$ versus $43.16 \pm 0.48 \mathrm{~g}$ $(\Delta=0.8 \%)$, when measured with and without the PMMA block.

Patient whole-body data. In both sexes, bt $=\mathrm{BMCt} / \mathrm{BMCti}$ and $\mathrm{lt}=\mathrm{LTMt} / \mathrm{LTM}$ ti were moderately correlated with $\mathrm{K}=$ W/Wi (Fig. 1), especially in males $(r \leq 0.55)$. These poor correlations were associated with the relatively small $\triangle \mathrm{BMCt}$ and $\Delta$ LTMt, roughly $10 \%$ and $20 \%$, respectively, whereas FMt more than doubled its normal values, as indicated by the mean bt, lt, and $\mathrm{ft}$ values given in Table 2 . As expected, BMCt was well correlated with LTMt $(r=0.93$ in females, and 0.94 in males). However, a low correlation was found between bt and lt ( $r=0.41$ in females and 0.30 in males). The distributions of bt, lt, and $\mathrm{ft}$, are shown in Figures 2 to 4 . The histograms drawn for bt values had a quite similar bell shape; however, the normality test failed $(p=0.020$ in females and $p=0.002$ in males). The peak values for bt were close in both sexes (Fig. 2). The distribution of lt values (Fig. 3) was

Table 1. Anatomical data of the subjects included in the study

\begin{tabular}{lcc}
\hline & $\begin{array}{c}\text { Females } \\
(n=298)\end{array}$ & $\begin{array}{c}\text { Males } \\
(n=198)\end{array}$ \\
\hline Chronological age (y) & & \\
Mean \pm 1 SD & $11.7 \pm 2.9$ & $11.6 \pm 2.8$ \\
Median & 11.8 & 11.9 \\
Range & $4.2-18.7$ & $3.5-16.7$ \\
$\mathrm{k}=\mathrm{H} / \mathrm{Ha}$ & $1.05 \pm 0.05$ & $1.05 \pm 0.05$ \\
$\mathrm{~K}=\mathrm{W} / \mathrm{Wi}$ & $1.55 \pm 0.24$ & $1.53 \pm 0.24$ \\
$\mathrm{BMI}$ & $29.2 \pm 5.5$ & $28.3 \pm 5.1$ \\
\hline
\end{tabular}

$\mathrm{H}$, actual ht in meters; Ha, normal ht for age; $\mathrm{W}$, actual wt in kilograms; Wi, normal wt for the actual ht; BMI = body mass index in $\mathrm{kg} / \mathrm{m}^{2}$.
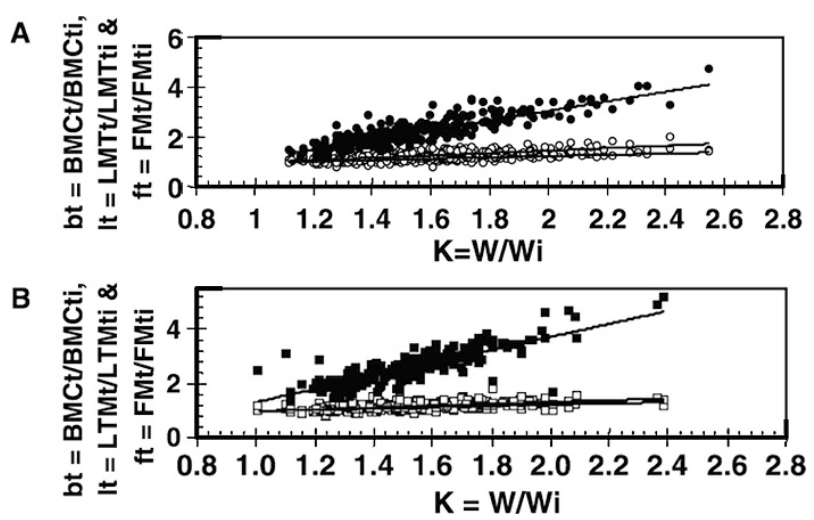

Figure 1. Linear correlations found between the ratios $b t=\mathrm{BMCt} / \mathrm{BMCti}$, $\mathrm{lt}=\mathrm{LTMt} / \mathrm{LMTi}$, and $\mathrm{ft}=\mathrm{FMt} / \mathrm{FMTi}$ (measured values divided by the corresponding values calculated for the ideal wt for ht, $\mathrm{Wi}$ ) and $\mathrm{K}=\mathrm{W} / \mathrm{Wi}$ in females $(A)$ and males $(B)$. bt $=0.269 \mathrm{~K}+0.692(r=0.59)$ in females (open circles) and $0.234 \mathrm{~K}+0.734(r=0.50)$ in males (open squares). $1 \mathrm{t}=$ $0.496 \mathrm{~K}+0.462(r=0.65)$ in females (shaded circles) and $0.333 \mathrm{~K}+0.637$ $(r=0.54)$ in males (shaded squares $) . \mathrm{ft}=1.939 \mathrm{~K}-0.833(r=0.86)$ in females (filled circles) and $2.411 \mathrm{~K}-1.114(r=0.83)$ in males (filled squares). While the body wt increased by 2.5 times the ideal wt for ht, the changes in BMC values were approximately of $+35 \%$ in females and $+20 \%$ in males. Fat mass values were well correlated with $\mathrm{K}$. Therefore, the equations of correlation found between $\mathrm{ft}$ and $\mathrm{K}$ values could be useful in clinical applications to estimate the supplement in fat mass in a given subject for whom $\mathrm{H}$ and $\mathrm{W}$ are known.

Table 2. Mean value $\pm 1 S D$ for the ratios $b t=B M C t / B M C t i$, $l t=L T M t / L T M t i$, and $f t=F M t / F M t i$, and for the ratios FMt/LTMt and Ft $(\%)=F M t / W$

\begin{tabular}{lll}
\hline & \multicolumn{1}{c}{ Females } & \multicolumn{1}{c}{ Males } \\
\hline $\mathrm{bt}=\mathrm{BMCt} / \mathrm{BMCti}$ & $1.11 \pm 0.11^{*}$ & $1.09 \pm 0.11^{*}$ \\
$\mathrm{lt}=\mathrm{LTMt} / \mathrm{LTMi}$ & $1.23 \pm 0.19^{*}$ & $1.15 \pm 0.15^{*}$ \\
$\mathrm{ft}=\mathrm{FMt} / \mathrm{FMti}$ & $2.17 \pm 0.54^{*}$ & $2.58 \pm 0.67^{*}$ \\
$\mathrm{FMt} / \mathrm{LTMt}$ & $1.03 \pm 0.26^{*}$ & $0.91 \pm 0.25^{*}$ \\
& $0.58 \pm 0.04$ & $0.40 \pm 0.00$ \\
$\mathrm{Ft}(\%)$ & $48.5 \pm 5.8^{*}$ & $45.8 \pm 7.5^{*}$ \\
& $35.8 \pm 1.9$ & $27.8 \pm 0.2$ \\
\hline
\end{tabular}

Data indicated in italics are mean normal values.

$\mathrm{i}$, index that stands for the mean values calculated for the ideal wt (Wi) for the actual ht $(\mathrm{H})-\mathrm{W}$ (actual wt).

* All the mean values given are significantly different in both sexes ( $p=$ 0.048 for bt and $p \leq 0.001$ for the other data).

different in females and males. In addition to the fact that the peak value for this parameter was lower in males than in females (1.15 versus 1.22 , as indicated in Table 2$)$, a trend toward higher lean values clearly appeared in the female distribution compared with the lt male distribution. Figure 4 shows that the distribution of $\mathrm{ft}$ values was also different in both sexes, with a trend toward higher values in boys than in girls.

The ratio FMt/LTMt was not dependent on age, and its mean values were 1.74 and 2.22 times higher than the mean values in controls in females and males, respectively, whereas fat presented quite similar percentage values of $48.0 \%$ and $45.4 \%$ of $\mathrm{W}$ (Table 2). In limbs, $\triangle \mathrm{BMCj}$ and $\Delta \mathrm{LTMj}(\mathrm{j}=\mathrm{a}$ and 1) values were higher in females than in males. Moreover, $\triangle \mathrm{BMCa}$ was lower than $\triangle \mathrm{BMCl}$. In both sexes, $\triangle \mathrm{LTMa}$ was higher than $\Delta$ LTMl. At the abdomen level, $\Delta$ LTMab was low and quite similar in both sexes $(+7 \%$ and $+5 \%)$. In all regions 


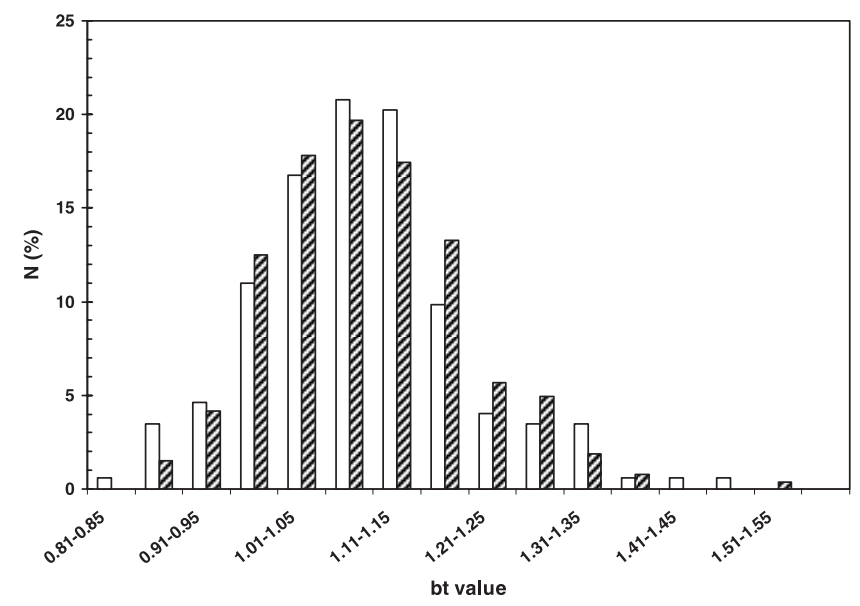

Figure 2. Distributions of the values for $\mathrm{bt}=\mathrm{BMCt} / \mathrm{BMCti}$, The histograms obtained for bt values had a gaussian shape in both sexes, with close peak values situated at approximately 1.10 , males $(\square)$, females ( $(\mathbb{Z})$.

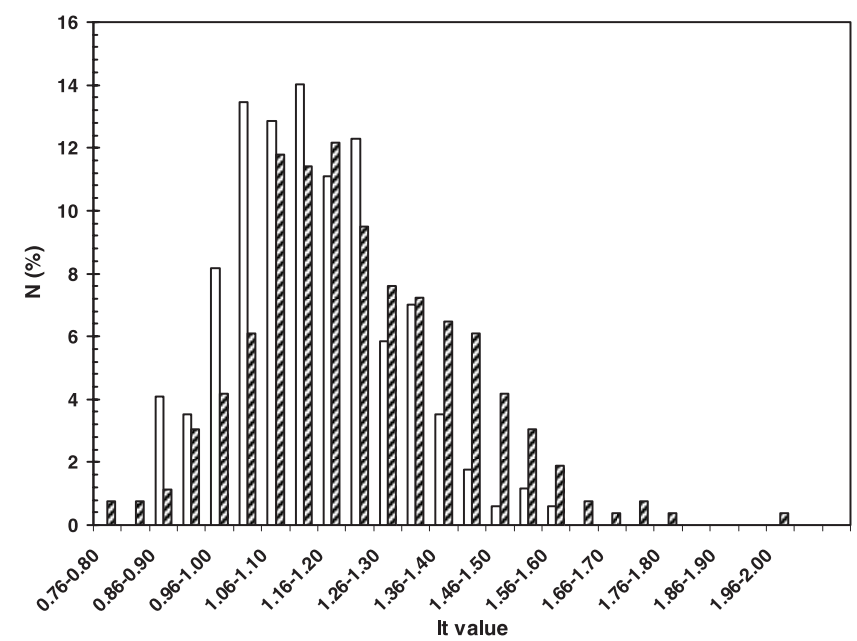

Figure 3. Distributions of the values for $1 t=\mathrm{LTMt} / \mathrm{LMTi}$. The $1 \mathrm{t}$ distributions were different in males $(\square)$ and females (שי $)$, with a peak value of 1.15 in males and 1.22 in females (whereas the mean values for $\mathrm{K}=\mathrm{W} / \mathrm{Wi}$ were $1.53 \pm 0.24$ in males and $1.55 \pm 0.24$ in females).

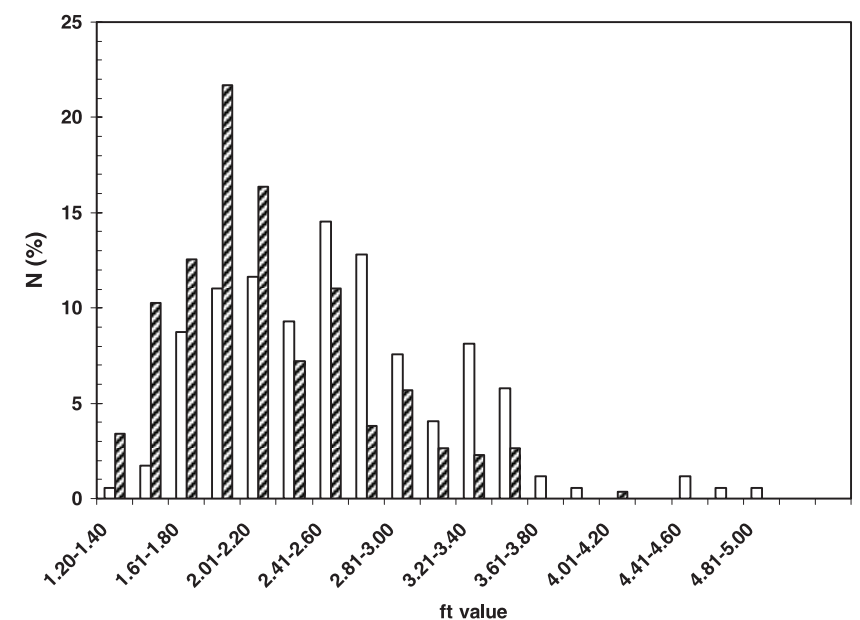

Figure 4. Distributions of the values for $\mathrm{ft}=\mathrm{FMt} / \mathrm{FMTi}$. A trend in $\mathrm{ft}$ values higher in males $(\square)$ than in females (沟) was observed.
Table 3. Mean value $\pm 1 S D$ for the ratios $b j=B M C j / B M C j i$, $l j=L T M j / L T M j i$, and $f j=F M j / F M j i$, in arms and legs $(j=a, 1)$ and for the ratios lab $=$ LTMab/LTMabi and fab $=$ FMab/FMabi at the abdomen level

\begin{tabular}{ccc}
\hline & Females & Males \\
\hline Arms & & \\
ba $=$ BMCa/BMCai & $1.12 \pm 0.16^{*}$ & $1.08 \pm 0.15^{*}$ \\
la $=$ LTMa/LTMai & $1.45 \pm 0.49^{*}$ & $1.24 \pm 0.35^{*}$ \\
fa $=$ FMa/FMai & $2.69 \pm 0.96^{*}$ & $3.09 \pm 1.02^{*}$ \\
Legs & & \\
bl $=$ BMCl/BMCli & $1.22 \pm 0.12^{*}$ & $1.17 \pm 0.12^{*}$ \\
ll $=$ LTMl/LTMli & $1.24 \pm 0.20^{*}$ & $1.15 \pm 0.16^{*}$ \\
fl $=$ FMl/FMli & $1.99 \pm 0.50^{*}$ & $2.36 \pm 0.65^{*}$ \\
Abdomen & & \\
lab $=$ LTMab/LTMabi & $1.07 \pm 0.18$ & $1.05 \pm 0.17$ \\
fab $=$ FMab/FMabi & $2.51 \pm 0.72^{*}$ & $3.44 \pm 1.03^{*}$ \\
\hline
\end{tabular}

$\mathrm{i}$, index stands for the mean values calculated for the ideal wt for ht, Wi.

* All the ratio values, except lab $(p=0.216)$, were significantly different in both sexes $(p \leq 0.005)$ for ba and $p \leq 0.001$ for the other ratio values.

Table 4. Distribution of the BMC, lean mass, and fat mass in the arms (a), legs (l), and abdomen (ab), expressed in percentage of the total $(t)$ corresponding values

\begin{tabular}{ccc}
\hline & Females & \multicolumn{1}{c}{ Males } \\
\hline Arms & & \\
BMCa/BMCt & $11.8 \pm 1.3$ & $11.9 \pm 1.5$ \\
& $11.6 \pm 0.3$ & $12.1 \pm 0.5$ \\
LTMa/LTMt & $11.5 \pm 4.9^{*}$ & $11.3 \pm 0.1^{*}$ \\
& $9.7 \pm 0.1$ & $12.8 \pm 0.1$ \\
FMa/FMt & $15.9 \pm 2.6^{*}$ & $15.2 \pm 2.1^{*}$ \\
& $13.0 \pm 0.1$ & $12.8 \pm 0.1$ \\
Legs & $35.5 \pm 2.3^{*}$ & $35.8 \pm 1.9^{*}$ \\
BMCl/BMCt & $32.0 \pm 1.3$ & $33.5 \pm 1.9$ \\
& $35.9 \pm 2.2$ & $36.1 \pm 2.5$ \\
LTM1/LTMt & $35.6 \pm 1.4$ & $36.0 \pm 1.4$ \\
& $35.5 \pm 0.7^{*}$ & $36.0 \pm 3.0^{*}$ \\
FM1/FMt & $38.6 \pm 0.7$ & $39.4 \pm 1.6$ \\
Abdomen & $19.6 \pm 1.5^{*}$ & $19.1 \pm 1.9^{*}$ \\
LTMab/LTMt & $22.4 \pm 0.2$ & $21.0 \pm 0.0$ \\
FMab/FMt & $22.5 \pm 2.2^{*}$ & $21.8 \pm 2.5^{*}$ \\
& $19.6 \pm 1.0$ & $16.4 \pm 1.0$
\end{tabular}

The mean values in controls are shown in italics.

* Significant differences between the measured and control values, at 95\% confidence interval $(p \leq 0.001)$.

of interest, and especially the abdomen, $\Delta \mathrm{FM}$ was much higher in boys than in girls (Table 3 ). The distribution of the BMC, LTM, and FMt in the arms, legs, and abdomen, characterized by the ratios of the three parameters $\mathrm{BMCj}, \mathrm{LTMj}$, and $\mathrm{FMj}(\mathrm{j}=\mathrm{a}, \mathrm{l}$, and $\mathrm{ab}$ ) to the total body corresponding values (t) was significantly different from that in controls, except for BMCa, and LTMl in both sexes (Table 4).

Finally, the head BMC represented $17.3 \pm 2.8 \%$ of $\mathrm{BMCt}$ in females and $17.9 \pm 3.5 \%$ in males (range, $10.3 \%-31.4 \%$ ), and after adjustment to take into account this noneffective part of BMC in the bearing skeleton, it was found that the wt Wskel, for which the skeleton would be appropriated, was higher than $\mathrm{Wi}$, by $15 \%$ in males and $18 \%$ in females, but 
lower than the actual wt W, by more than $20 \%$ in both sexes (Table 5).

\section{DISCUSSION}

Patient data. The population studied was composed of 198 males and 298 females. Interestingly, the sex ratio, which was not defined a priori for the patient recruitment in this study, was 0.66 , a value close to that $(0.63)$ indicated by Rinderknecht and Smith (24) in a study of 155 youths who wanted to be thinner. The age range of our patients covered childhood and adolescence, with mean and median ages around $12 \mathrm{y}$. These are important periods of life for skeleton growth and the continuous development of a healthy body composition in lean and fat masses. Moreover, it has been shown that obesity acquired at these ages is likely to continue in adulthood to some degree in more than $50 \%$ of cases $(25,26)$ and with an increase of cardiovascular risk $(27,28)$. The subjects in this study were taller than controls for age by approximately 1 SD. A similar fact was also noted by Freedman et al., who estimated that each SD increase in ht for age was associated with a 4.6-fold increase in the prevalence of overweight 5- to 8-y-old boys, and a 10-fold difference was found in the prevalence of overweight across quintiles of ht in children between the ages of 3 and 10 y $(29,30)$. The actual wt of the subjects in our population was higher than their ideal wt for ht by approximately $50 \%$ (e.g. about 4.5 SDs). However, these large differences with the normality were not correlated with age. This finding indicates that significant overweight can be established early in the childhood period.

Phantom measurements. Studies have shown that possible anomalous bone results may be due to fat distribution alterations (31), a control of our DXA system response was performed on a phantom. The superposition of a PMMA block on the spine phantom used for the daily system calibration increased the measured lean and fat mass values of this phantom by a factor of 3.0 and 3.8, respectively. In the present study, however, the corresponding changes in the measured BMD and BMC values were $+0.7 \%$ and $+0.8 \%$, respectively. Although these changes were significant $(p<0.05)$, they should be interpreted with regard to the precision of the DXA system, which was calculated to be $0.59 \%$ in vitro (23). The introduction of a correction factor appeared therefore unnecessary.

Whole-body DXA data. The whole-body data were analyzed by using the ideal mean wt for ht, Wi, and reference data calculated from the equations defined in controls (23). This makes it easy to show possible alterations in BMCj, LTMj, and $\mathrm{FMj}$. Even though BMI is widely used to characterize

Table 5. Theoretical body wt corresponding to the actual bearing skeleton

\begin{tabular}{lcc}
\hline & Females & Males \\
\hline Wskel/Wi & $1.19 \pm 0.11$ & $1.15 \pm 0.10$ \\
Wskel/W & $0.78 \pm 0.09$ & $0.76 \pm 0.10$ \\
\hline
\end{tabular}

Mean value $\pm 1 \mathrm{SD}$ for the ratios Wskel/Wi and Wskel/W, where Wskel would be the body wt appropriated to the actual BMC of the bearing skeleton. $\mathrm{W}$, actual wt; Wi, ideal wt for the actual ht, $\mathrm{H}$. adiposity (32), we did not consider only this parameter for the analysis of our data. In fact, $\mathrm{BMI}=\mathrm{W} / \mathrm{H}^{2}=(\mathrm{BMCt}+\mathrm{LTMt}+$ $\mathrm{FMt}) / \mathrm{H}^{2}$. Therefore, in every case, a significant correlation must be found between BMI and FMt. Moreover, the higher FMt values are, the better the correlation should be. This is certainly the reason why in some studies it has been found that BMI identified obese but not overweight children for whom the screening sensitivity of BMI was poor (33), and up to $32 \%$ of females and $42 \%$ of male adolescents classified as overweight or obese do not present important adiposity (34). Moreover, the changes in BMI values during growth $(35,36)$ show a decrease until age $6-7$, at which a minimum value is found, followed by a nonlinear increase. This variation makes BMI not of very high interest in the growth period in cases of growth advance or retardation. Conversely, wt for ht presents a simple monotonic mathematical relation with $\mathrm{W}$, and its performance in predicting underweight or overweight in children and adolescents is similar to BMI (37).

$\Delta \mathrm{BMCt}$ values were poorly correlated with $\mathrm{K}=\mathrm{W} / \mathrm{Wi}$, apparently indicating that the skeleton cannot adapt to a wide range of wt changes. It should be considered, however, that some parts of the skeleton, which are not submitted to mechanical stresses, do not have to change significantly under wt alterations. This is especially true for the head, which makes up about $30 \%$ of BMCt between ages 3.5 and 18, as previously shown (Braillon et al., ASBMR meeting, September 1993, Tampa, FL) and found again in this study. Therefore, the theoretical wt Wskel that would correspond to the mechanical aptitude of the skeleton was estimated by using the value of BMCt-h = BMCt - head BMC, a quantity that can be considered representative of the $\mathrm{BMC}$ of the bearing skeleton. This way, it was found that, despite a mean increase of about $10 \%$, the BMC of the bearing skeleton remained $22 \%$ to $25 \%$ below the value, which would be adapted to the actual wt of the patients.

The ratio $\mathrm{lj}=\mathrm{LTMj} / \mathrm{LTMji}$ and the associated ratio $\mathrm{fj}=$ FMj/FMji are two sensitive indexes to quantify the lean and fat alterations in both sexes. The larger increase of $\mathrm{ft}$ in males than in females, with respect to the mean values in controls, was finally a trend toward equalizing the proportion of fat in both sexes. This trend also appeared clearly in the differences in FMt/LTMt and FMt percentages, which were of approximately $10 \%$ and $5 \%$ between male and female patients, while they were of $31 \%$ and $22 \%$ in our reference population.

In limbs, $\triangle \mathrm{BMCl}$ values were two times higher than $\triangle \mathrm{BMCa}$ values, a fact that strengthens the important influence of wt on bone dimension changes (38). However, in both sexes, $\triangle$ LTMa values were higher than $\Delta$ LTMl values. In addition, $\Delta$ FMa values were higher than $\Delta \mathrm{FMl}$ values by approximately $30 \%$ and were higher in males than in females. At the abdomen level, although $\Delta$ LTMab values were of low magnitude and similar in both sexes, $\Delta$ FMab values were close to 2.5 times and 3.5 times the normal values in females and males, respectively. At this level, it has been shown that the excess in adiposity is predominantly found in subcutaneous tissue (39). The assessment of abdominal fat with DXA techniques cannot discriminate the subcutaneous fat from intra-abdominal adipose tissue (40). However, in a magnetic 
resonance study conducted by Brambilla et al. (41) in obese adolescents over a 4-y period, it was shown that intraabdominal fat did not change significantly whereas subcutaneous adipose tissue increased significantly. Thus, it can be considered that measurements of the total abdominal fat mass by DXA is a reasonable approach with sufficient sensitivity to follow the possible changes in body composition. Finally, the high fat mass values found in major body regions in overweight boys yielded similar total fat percentage values in males and females and similar ratio values for FMt/LTMt, an aspect that could have important consequences on the risk of diseases and especially diseases related to insulin resistance syndrome (42).

This study had some limitations. It was a case-control study. However, the control group and the patients included in the study were from the same general population. In addition, biological tests that could help to explain some differences between girls and boys, especially in fat trend, were not predefined and were missing.

Conversely, the analysis of the data were made by using a simple method based on the fact that, for a given patient ht, a normal wt and normal BMC, LTM, and FM values can be used as reference data. This approach had the advantage that physiologic changes in these parameters, especially at the time of puberty, were automatically taken into account as they are directly linked to the changes in ht. In addition, the results, expressed as ratios, are probably not dependent of the DXA system used.

In conclusion, in overweight subjects, the differences in BMC and lean and fat masses in normal youths are sex dependent. Moreover, in this population, the fat mass accretion is greater in males than in females and finally yielded similar body fat proportions in both sexes.

In clinical practice, the challenge is to manage the body wt of overweight patients as close as possible to its appropriate value during growth. The BMC of the bearing skeleton, especially legs, and the ratio FMt over LTMt might be important parameters to consider. However, as a first step, the wt for which the bearing skeleton should be adapted seemed a reasonable goal to achieve in this population of youths.

\section{APPENDIX 1}

Ideal weight (Wi in kilograms) for the actual ht $(\mathrm{H}$ in meters, obtained with three digits): females, $2.230 \times \operatorname{Exp}$ $(1.930 \times \mathrm{H})$; males, $2.413 \times \operatorname{Exp}(1.868 \times \mathrm{H})$.

\section{APPENDIX 2}

Equations to calculate the mean body wt (Wskel) that would be in agreement with the measured BMC of the bearing skeleton, defined here as BMCt-h (BMCt less the head BMC), Wiskel: females, $26.9 \times$ BMCt-h +3420 ; males, $25.3 \times$ BMCt-h + 4850.

\section{REFERENCES}

1. Freedman DS, Srinivasan SR, Valdez RA, Williamson DF, Berenson GS 1997 Secular increases in relative weight and adiposity among children over two decades: the Bogalusa Heart Study. Pediatrics 99:420-426
2. Troiano RP, Flegal KM 1998 Overweight children and adolescents: description, epidemiology and demographics. Pediatrics 101:497-504

3. Livingstone B 2000 Epidemiology of childhood obesity in Europe. Eur J Pediatr 159:S14-S34

4. Strauss RS, Pollack HA 2001 Epidemic increase in childhood overweight, 19861998. JAMA 12:2845-2848

5. Sakamoto N, Wansorn S, Tontisirin K, Marui E 2001 A social epidemiologic study of obesity among preschool children in Thailand. Int J Obes Relat Metab Disord 25:389-394

6. Tremblay MS, Katzmarzyk PT, Willms JD 2002 Temporal trends in overweight and obesity in Canada, 1981-1996. Int J Obes Relat Metab Disord 26:538-543

7. Kautiainen S, Rimpelä A, Vikat A, Virtanen SM 2002 Secular trends in overweight and obesity among Finnish adolescents in 1977-1999. Int J Obes Relat Metab Disord 26:544-552

8. Wang Y, Monteiro C, Popkin BM 2002 Trends of obesity and underweight in older children and adolescents in the United States, Brazil, China, and Russia. Am J Clin Nutr 75:971-977

9. Wang G, Dietz WH 2002 Economic burden of obesity in youths aged 6 to 17 years: 1979-1999. Pediatrics 109:E81

10. Drake AJ, Smith A, Betts PR, Crowne EC, Shield JP 2002 Type 2 diabetes in obese white children. Arch Dis Child 86:207-208

11. Sinha R, Fisch G, Teague B, Tamborlane WV, Banyas B, Allen K, Savoye M, Rieger V, Taksali S, Barbetta G, Sherwin RS, Caprio S 2002 Prevalence of impaired glucose tolerance among children and adolescents with marked obesity. N Engl J Med 346:802-810

12. Goran MI, Gall GD, Cruz M 2003 Obesity and risk of type 2 diabetes and cardiovascular disease in children and adolescents. J Clin Endocrinol Metab 88:1417-1427

13. Buiten C, Metzger B 2000 Childhood obesity and risk of cardiovascular disease: a review of the science. Pediatr Nurs 26:13-18

14. Burke V 2006 Obesity in childhood and cardiovascular risk. Clin Exp Pharmacol Physiol 33:831-837

15. Njeh CF, Samat SB, Nightingale A, McNeil EA, Boivin CM 1997 Radiation dose and in vitro precision in paediatric bone mineral density measurement using dual X-ray absorptiometry. Br J Radiol 70:719-727

16. Mazess RB, Barden HS, Bisek JP, Hanson J 1990 Dual energy X-ray absorptiometry for total-body and regional bone-mineral and soft tissue composition. Am J Clin Nutr 51:1106-1112

17. Treuth MS, Butte NF, Wong WW, Ellis KJ 2001 Body composition in prepubertal girls: comparison of six methods. Int J Obes Relat Metab Disord 25:1352-1359

18. Kitano T, Kitano N, Inomoto T, Futatsuka M 2001 Evaluation of body composition using dual energy X-ray absorptiometry, skinfold thickness and bioelectrical impedance analysis in Japanese female college students. J Nutr Sci Vitaminol (Tokyo) 47:122-125

19. Black A, Tilmont EM, Baer DJ, Rumpler WV, Ingram DK, Roth GS, Lane MA 2001 Accuracy and precision of dual-energy X-ray absorptiometry for body composition measurements in rhesus monkeys. J Med Primatol 30:94-99

20. Speakman JR, Booles D, Butterwick R 2001 Validation of dual energy X-ray absorptiometry (DXA) by comparison with chemical analysis of dogs and cats. Int J Obes Relat Metab Disord 25:439-447

21. Braillon P, Lapillonne A, Giraud S, Salle BL, Cochat P 1998 Precision of body composition measurements by dual energy X-ray absorptiometry. Appl Radiat Isot 49:501-502

22. Houtkooper LB, Going SB, Sproul J, Blew RM, Lohman TG 2000 Comparison of methods for assessing body-composition changes over $1 \mathrm{y}$ in postmenopausal women. Am J Clin Nutr 72:401-406

23. Braillon PM 2003 Annual changes in bone mineral content and body composition during growth]. Horm Res 60:284-290

24. Rinderknecht K, Smith C 2002 Body-image perceptions among urban Native American youth. Obes Res 10:315-327

25. Rimm IJ, Rimm AA 1976 Association between juvenile onset obesity and severe adult obesity in 73,532 women. Am J Public Health 66:479-481

26. Togashi K, Masuda H, Rankinen T, Tanaka S, Bouchard C, Kamiya H 2002 A 12-year follow-up study of treated obese children in Japan. Int J Obes Relat Metab Disord 26:770-777

27. Freedman DS, Shear CL, Burke GL, Srinivasan SR, Webber LS, Harsha DW, Berenson GS 1987 Persistence of juvenile onset obesity over eight years: the Bogalusa Heart Study. Am J Public Health 77:588-592

28. Sivanandam S, Sinaiko AR, Jacobs DR Jr, Steffen L, Moran A, Steinberger J 2006 Relation of increase in adiposity to increase in left ventricular mass from childhood to young adulthood. Am J Cardiol 98:411-415

29. Freedman DS, Thornton JC, Mei Z, Wang J, Dietz WH, Pierson RN Jr, Horlick M 2004 Height and adiposity among children. Obes Res 12:846-853

30. Freedman DS, Khan LK, Serdula MK, Dietz WH, Srinivasan SR, Berenson GS 2004 Inter-relationships among childhood BMI, childhood height, and adult obesity: the Bogalusa Heart Study. Int J Obes Relat Metab Disord 28:10-16

31. Tothill P 2005 Dual-energy X-ray absorptiometry measurements of total-body bone mineral during weight change. J Clin Densitom 8:31-38

32. Pietrobelli A, Faith MS, Allison DB, Gallagher D, Chiumello G, Heymsfield SB 1998 Body mass index as a measure of adiposity among children and adolescents: a validation study. J Pediatr 132:204-210

33. Mast M, Langnase K, Labitzke K, Bruse U, Preuss U, Muller MJ 2002 Use of BMI as a measure of overweight and obesity in a field study on 5-7 year old children. Eur J Nutr 41:61-67 
34. Rodriguez G, Moreno LA, Blay MG, Blay VA, Garagorri JM, Sarria A, Bueno M 2004 Body composition in adolescents: measurements and metabolic aspects. Int J Obes Relat Metab Disord 28:S54-S58

35. Rolland-Cachera MF, Cole TJ, Sempe M, Tichet J, Rossignol C, Charraud A 1991 Body mass index variations: centiles from birth to 87 years. Eur J Clin Nutr 45:13-21

36. Kuczmarski RJ, Ogden CL, Grummer-Strawn LM, Flegal KM, Guo SS, Wei R, Mei Z, Curtin LR, Roche AF, Johnson CL 2000 CDC growth charts: United States. Adv Data 8:1-27

37. Mei Z, Grummer-Strawn LM, Pietrobelli A, Goulding A, Goran MI, Dietz WH 2002 Validity of body mass index compared with other body-composition screening indexes for the assessment of body fatness in children and adolescents. Am J Clin Nutr 75:978-985
38. Leonard MB, Shults J, Wilson BA, Tershakovec AM, Zemel BS 2004 Obesity during childhood and adolescence augments bone mass and bone dimensions. Am J Clin Nutr 80:514-523

39. Fox K, Peters D, Armstrong N, Sharpe P, Bell M 1993 Abdominal fat deposition in 11-year-old children. Int J Obes Relat Metab Disord 17:11-16

40. Goran MI, Gower BA 1999 Relation between visceral fat and disease risk in children and adolescents. Am J Clin Nutr 70:149S-156S

41. Brambilla P, Manzoni P, Agostini G, Beccaria L, Ruotolo G, Sironi S, Del Maschio A, Chiumello G 1999 Persisting obesity starting before puberty is associated with stable intra-abdominal fat during adolescence. Int J Obes Relat Metab Disord 23:299-303

42. Dietz WH 1998 Health consequences of obesity in youth: childhood predictors of adult disease. Pediatrics 101:518-525 